\title{
Metabolic engineering of Escherichia coli for the biosynthesis of alpha-pinene
}

\author{
Jianming Yang ${ }^{1}$, Qingjuan $\mathrm{Nie}^{2}$, Meng Ren ${ }^{3}$, Hongru Feng ${ }^{4}$, Xinglin Jiang ${ }^{1}$, Yanning Zheng ${ }^{1}$, Min Liư ${ }^{5}$, \\ Haibo Zhang ${ }^{1 *}$ and Mo Xian ${ }^{1 *}$
}

\begin{abstract}
Background: a-Pinene is an important natural product that is widely used in flavorings, fragrances, medicines, fine chemicals and high-density renewable fuels. Currently, a-Pinene used in industry is mainly produced either by tapping trees (gum turpentine) or as a byproduct of paper pulping (crude sulfate turpentine, CST). However, the extraction of it from trees is tedious and inefficient and requires substantial expenditure of natural resources. Therefore, it is necessary to seek sustainable technologies for a-pinene production.

Results: To construct the microbial synthetic pathway of a-pinene in E. coli, we co-expressed native geranyl diphosphate synthase (IspA) from E. coli and a-pinene synthase (Pt30) from Pinus taeda, and then to increase the geranyl diphosphate (GPP) content in the cells, a suitable geranyl diphosphate synthase (GPPS2) was selected from two different origins. Furthermore, to enhance a-pinene production, a novel biosynthetic pathway of a-pinene was assembled in E. coli BL21(DE3) with the heterologous hybrid mevalonate (MVA) pathway, GPPS2 and a-pinene synthase (Pt30). The final genetic strain, YJM28, harboring the above novel biosynthetic pathway of a-pinene, accumulated a-pinene up to $5.44 \mathrm{mg} / \mathrm{L}$ and $0.97 \mathrm{~g} / \mathrm{L}$ under flask and fed-batch fermentation conditions, respectively. The conversion efficiency of glucose to a-pinene (gram to gram) in the metabolically engineered strain reached $2.61 \%$.
\end{abstract}

Conclusions: In this paper, by using metabolic engineering techniques, the more efficient biosynthetic pathway of a-pinene was successfully assembled in E. coli BL21(DE3) with the heterologous hybrid MVA pathway, GPPS2 and a-pinene synthase (Pt30). In addition, this is the first report on a-pinene fed-batch fermentation, and our results represent improvements over previous reports.

Keywords: a-Pinene, Geranyl diphosphate synthase, a-Pinene Synthase, E. coli

\section{Background}

$\alpha$-Pinene is a natural and active monoterpene, which is derived from the head-to-tail condensation of dimethylallyl pyrophosphate (DMAPP) and isopentenyl pyrophosphate (IPP) [1]. $\alpha$-Pinene is an important natural product that is widely used in flavorings, fragrances [2], medicines and fine chemicals $[3,4]$. Because of its compact structure and reactive olefin functionality, it also has some potential as a feedstock for high-density renewable fuels such as jet fuel $[5,6]$.

Monoterpenes such as $\alpha$-pinene, $\beta$-pinene, camphene, and limonene are important components of pine resin and are currently produced on an industrial scale either

\footnotetext{
*Correspondence: zhanghb@qibebt.ac.cn; xianmo@qibebt.ac.cn ${ }^{1}$ Qingdao Institute of Bioenergy and Bioprocess Technology, Chinese Academy of Sciences, Qingdao 266101, China

Full list of author information is available at the end of the article
}

by tapping trees (gum turpentine) or as a byproduct of paper pulping (crude sulfate turpentine, CST) [2]. However, the extraction of these molecules from plants is tedious and inefficient and requires substantial expenditure of natural resources because of their low content [7]. Consequently, there is much interest in developing technologies that could engineer microorganisms to convert renewable resources, such as glucose generated from cellulose or hemicellulose, into monoterpene products [8]. By comparison with traditional methods, microbial synthesis of $\alpha$-pinene seems likely to become successful primarily because microorganisms have the advantages of fast growth, no need for land during their growth and sustainable development $[9,10]$.
C Biomed Central 
Like other monoterpenes, $\alpha$-pinene is generated from the common precursor of IPP and DMAPP, which can be produced from two different pathways: the methylerythritol 4-phosphate (MEP) pathway and the mevalonate (MVA) pathway (Figure 1) [11]. Although many microorganisms carry out the MEP pathway or MVA pathway to supply the intermediates DMAPP and IPP, they are unable to produce the monoterpenes because of the absence of monoterpene synthase. With the substantial improvement of metabolic engineering, many research labs have explored biosynthetic methods of monoterpene production by introducing heterologous monoterpene synthase: for instance, 3-carene and limonene. Reiling et al. demonstrated that an engineered $E$. coli strain that overexpresses native 1-deoxy-D-xylulose-5-phosphate (DXP) synthase (DXS) and IPP isomerase (IPIHp) from Haematococcus pluvialis, geranyl diphosphate synthase (IspA) from E. coli and 3-carene cyclase from Picea abies can accumulate a 3 -carene titer of about $3 \mu \mathrm{g} / \mathrm{L} / \mathrm{OD}_{600}$ after $8 \mathrm{~h}$ production [12]. By using the native MEP pathway to supply the precursor of DMAPP and IPP, Carter et.al. introduced a monoterpene biosynthesis pathway into E. coli, which led to about $5 \mathrm{mg} / \mathrm{L}$ limonene production [13].

Although great success has been achieved in monoterpene production by using the MEP pathway, this approach remains inefficient owing to regulatory mechanisms present in the native host [14]. This limitation was also confirmed by experiments on isoprene production using the MEP or MVA pathway $[15,16]$.

\section{Results and discussion}

In this paper, $\alpha$-pinene production was significantly enhanced by assembling a biosynthetic pathway of $\alpha$-pinene using the heterologous MVA pathway and the GPPS2 and Pt30 genes in an engineered E.coli strain. The final genetic strain, YJM28, containing the biosynthetic pathway of $\alpha$-pinene, accumulated $\alpha$-pinene up to $5.44 \mathrm{mg} / \mathrm{L}$ and $0.97 \mathrm{~g} / \mathrm{L}$ under flask and fed-batch fermentation conditions, respectively. The conversion efficiency of glucose to $\alpha$-pinene (gram to gram) reached $2.61 \%$. To our knowledge, this is the first report on $\alpha-$ pinene fed-batch fermentation, and our results represent improvements over previous reports. Thus, an alternative production system for $\alpha$-pinene from renewable sources via the MVA pathway in $E$. coli has been provided.

\section{Characterization of a-pinene by GC-MS}

Although E. coli possesses a native MEP pathway that supplies the intermediates DMAPP and IPP, it cannot produce $\alpha$-pinene because of the absence of $\alpha$-pinene synthase. Consequently, to synthesize $\alpha$-pinene, $\alpha$-pinene synthase (Pt30) derived from Pinus taeda was introduced into the E. coli strain. However, after $40 \mathrm{~h}$ of incubation of the modified strain, the target product could not be measured by GC-MS (data not shown). The main reason for this result might be the failure to detect $\alpha$-pinene since its production was too low as a result of the insufficiency of GPP. Hence, to enhance the supply of GPP, the native gene $i s p A$ from $E$. coli, which encodes geranyl diphosphate synthase, which catalyzes the conversion of DMAPP and IPP into GPP, was combined with the $\alpha$ pinene synthase gene (Pt30) and ligated into pACYDUet1 to create the plasmid pYJM23 (pACY-ispA-Pt30). The E. coli strain containing PYJM23 was inoculated in the fermentation medium and incubated at $37^{\circ} \mathrm{C}$ with shaking at $180 \mathrm{rpm}$. When its $\mathrm{OD}_{600}$ (cell culture optical density measured at $600 \mathrm{~nm}$, one $\mathrm{OD}_{600}$ unit approximately corresponded to $0.43 \mathrm{~g} \mathrm{~L}^{-1}$ of dry cell weight) reached 0.6 , IPTG was added to a final concentration of $1 \mathrm{mM}$, and culture was further maintained at $30^{\circ} \mathrm{C}$ for $24 \mathrm{~h}$. The off-gas from the headspace of the sealed cultures was tested by GC-MS. As shown in Figure 2, based on the relative retention time and total ion mass spectral comparison with an external standard, the engineered $E$. coli strain carrying the native ispA gene and Pt30 from Pinus

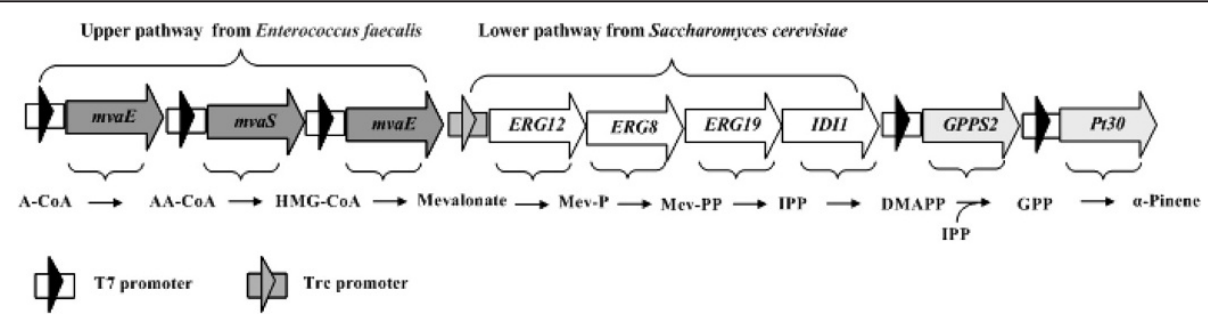

Figure 1 Production of a-pinene via the MVA pathways used in this study. Gene symbols and the enzymes they encode (all genes marked with gray arrows were from Enterococcus faecalis, all genes marked with white arrows were isolated from Saccharomyces cerevisiae and the gene marked with light gray arrows derived from Abies grandis or Pinus taeda). MVA pathway: MvaE, acetyl-CoA acetyltransferase /HMG- CoA reductase; MvaS, HMG-CoA synthase; ERG12, mevalonate kinase; ERG8, phosphomevalonate kinase; ERG19, mevalonate pyrophosphate decarboxylase; IDI1, IPP isomerase;GPPS2, Abies grandis geranyl diphosphate synthase was optimized to the preferred codon usage of E. coli; Pt30, Pinus taeda alphapinene synthase was optimized to the preferred codon usage of $E$. coli. Pathway intermediates. MVA pathway: A-CoA, acetyl-CoA; AA-CoA, acetoacetyl-CoA; HMG-CoA, hydroxymethylglutaryl-CoA; Mev-P, mevalonate 5-phosphate; Mev-PP, mevalonate pyrophosphate. IPP, isopentenyl pyrophosphate; DMAPP, dimethylallyl pyrophosphate; GPP, geranyl diphosphate. 


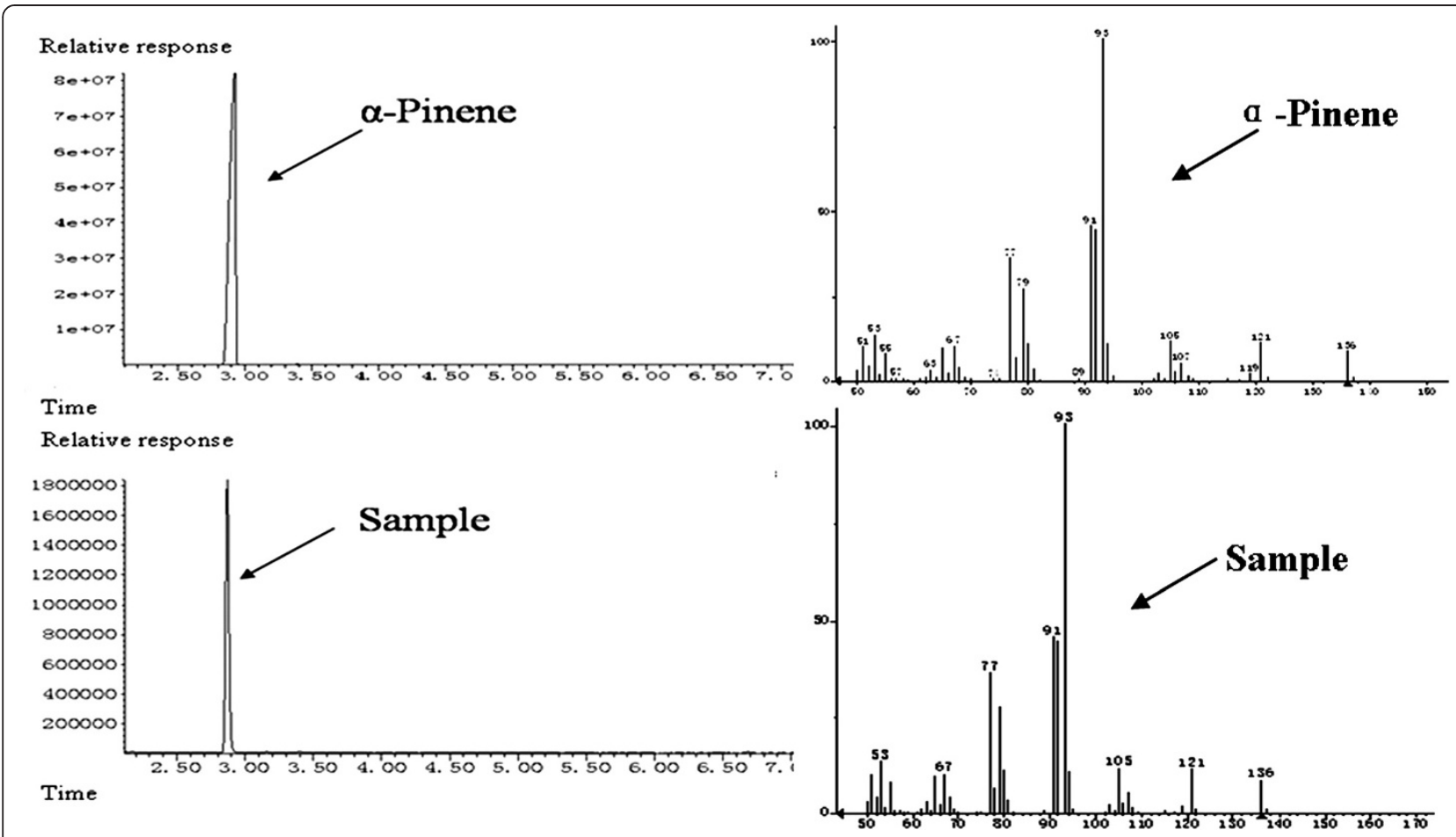

Figure 2 GC-MS analysis of sample from the headspace of the sealed cultures of strain YJM26. When $\mathrm{OD}_{600}$ reached 0.6-0.9, cultures were induced at $30^{\circ} \mathrm{C}$ for $24 \mathrm{~h}$ using $1 \mathrm{mM} \mathrm{IPTG}$.

taeda produced $\alpha$-pinene in detectable quantities. Thus, the biosynthetic pathway for $\alpha$-pinene production was successfully constructed using the MEP pathway and Pt30 from Pinus taeda.

\section{Screening of geranyl diphosphate synthases}

As an important metabolic precursor of the monoterpenes, geranyl diphosphate (GPP) is generated from the condensation of dimethylallyl diphosphate and isopentenyl diphosphate, catalyzed by GPPS, which is regarded as a short-chain prenyltransferase that functions at the branch points of isoprenoid metabolism [1]. An effective method to optimize pathway efficiency may be to use genes from different organisms [17]. In this study, the GPPS enzymes from E. coli and Abies grandis were evaluated to enhance the supply of GPP.

Because of the difficulty in detecting and quantifying GPP, the GPPS2 gene from Abies grandis or ispA gene from $E$. coli was ligated with the $\alpha$-pinene synthase gene (Pt30) to create the plasmid pYJM25(pACY-GPPS2-Pt30) or pYJM23 (pACY-ispA-Pt30), respectively. The strains YJM26 (carrying pYJM23), YJM27 (carrying PYJM25), and YJM29(carrying pYJM28) were cultured in 100-ml shakeflasks. When each culture reached an $\mathrm{OD}_{600}$ of 0.6 , expression of GPP synthase and $\alpha$-pinene synthase was induced by $0.5 \mathrm{mM}$ IPTG. Meanwhile, $200 \mu \mathrm{M}$ DMAPP and IPP were added into the medium, and the culture was further incubated at $30^{\circ} \mathrm{C}$ for $24 \mathrm{~h}$. A noticeable difference in $\alpha$-pinene production was observed. The E. coli strain YJM27 harboring GPPS2 and Pt30 genes produced $1.35 \mathrm{mg} \alpha$-pinene per liter of bacterial culture, which was about 8-fold higher than strain YJM26 harboring ispA and Pt30 genes $(0.172 \mathrm{mg} / \mathrm{L})$, whereas the E. coli strain(YJM29) carrying only the $\alpha$-pinene synthase generated no detectable $\alpha$-pinene. This result demonstrates that the exogenous expression of geranyl diphosphate synthase contributed to the $\alpha$-pinene production, and the enzyme activity of GPPS2 from Abies grandis was higher than that of IspA from $E$. coli BL21(DE3). Hence, the GPPS2 enzyme was selected to enhance GPP production in the following experiments.

\section{Biosynthesis of a-pinene using the MVA pathway}

In previous experiments, a hybrid exogenous MVA pathway has been assembled in engineered E.coli strains to produce isoprene [15]. Based on previous experimental data, the hybrid exogenous MVA pathway is effective to synthesize DMAPP and IPP. Consequently, we hypothesized that the engineered strain with the hybrid exogenous MVA pathway could further enhance the production of $\alpha$-pinene.

To test the effect of the MVA pathway on the production of $\alpha$-pinene, the recombinant strain YJM28 (E. coli harboring the MVA pathway, GPPS and $\alpha$-pinene synthase) and strain YJM27 (E. coli harboring GPPS synthase and $\alpha-$ pinene synthase) were cultured in fermentation medium 
under shake-flask conditions. The amount of $\alpha$-pinene accumulated in the culture media from different recombinant strains was calculated according to a standard curve plotted with a set of known concentrations of $\alpha$-pinene. The $\alpha$ pinene concentration of strain YJM28 reached $0.65 \mathrm{mg} / \mathrm{L}$ after being induced by $0.5 \mathrm{mM}$ IPTG for $24 \mathrm{~h}$, while strain YJM27 (without the MVA pathway) produced only a small amount of end product (data not shown). These results indicate that the hybrid MVA pathway caused a considerable increase in $\alpha$-pinene production.

\section{Optimization of fermentation conditions}

Fermentation conditions are of great importance because they play a vital role in the formation, concentration and yield of end product [18]. Optimizing fermentation conditions for strains is a good way to improve product quality and quantity.

The one-factor-at-a-time method is a closed-ended system for fermentation processes. Based on the classical method of changing one independent variable while fixing all others $[19,20]$, this method can be applied to optimization of medium components as well as to optimization of process conditions. In view of its easy operation and convenience, the one-factor-at-a-time method has become the most popular method for improving fermentation media and process conditions. In this paper, the three most important factors, induction temperature, inducer concentration and organic nitrogen source, were optimized to improve $\alpha$-pinene production, using the strain YJM28.

\section{Effect of induction temperature on a-pinene production}

Low induction temperatures $\left(30^{\circ} \mathrm{C}\right.$ or $\left.25^{\circ} \mathrm{C}\right)$ can enhance the activities of recombinant enzymes because low temperatures decrease the inclusion bodies in genetically engineered E. coli $[21,22]$. However, a successful control of cultivation temperature has to balance the enzyme expression, cell growth and product formation [23]. Hence, in this study, to increase $\alpha$-pinene production, the induction temperatures of $25^{\circ} \mathrm{C}, 30^{\circ} \mathrm{C}, 34^{\circ} \mathrm{C}$, and $37^{\circ} \mathrm{C}$ were tried. As shown in Figure 3, the maximum $\alpha$-pinene production was observed at $30^{\circ} \mathrm{C}$, at $1.31 \mathrm{mg} / \mathrm{L}$, which was about 1.5 times, 5 times and 8 times greater than those observed at $25^{\circ} \mathrm{C}(0.86 \mathrm{mg} / \mathrm{L}), 34^{\circ} \mathrm{C}(0.26 \mathrm{mg} / \mathrm{L})$ and $37^{\circ} \mathrm{C}$ $(0.165 \mathrm{mg} / \mathrm{L})$, respectively. Hence, the optimum induction temperature for $\alpha$-pinene production was $30^{\circ} \mathrm{C}$.

\section{Effect of inducer concentration on a-pinene production}

Exogenous gene expression generally causes a metabolic burden on the cell, which can result in reduced growth rates, cell yields, product expression, and plasmid stability $[24,25]$. The level of IPTG used can be varied to adjust the extent of the metabolic burden imposed on the cell [26]. Based on these considerations, various IPTG concentrations, ranging from $0.1 \mathrm{mM}$ to $1 \mathrm{mM}$, were tested to optimize the inducer concentration at the above-

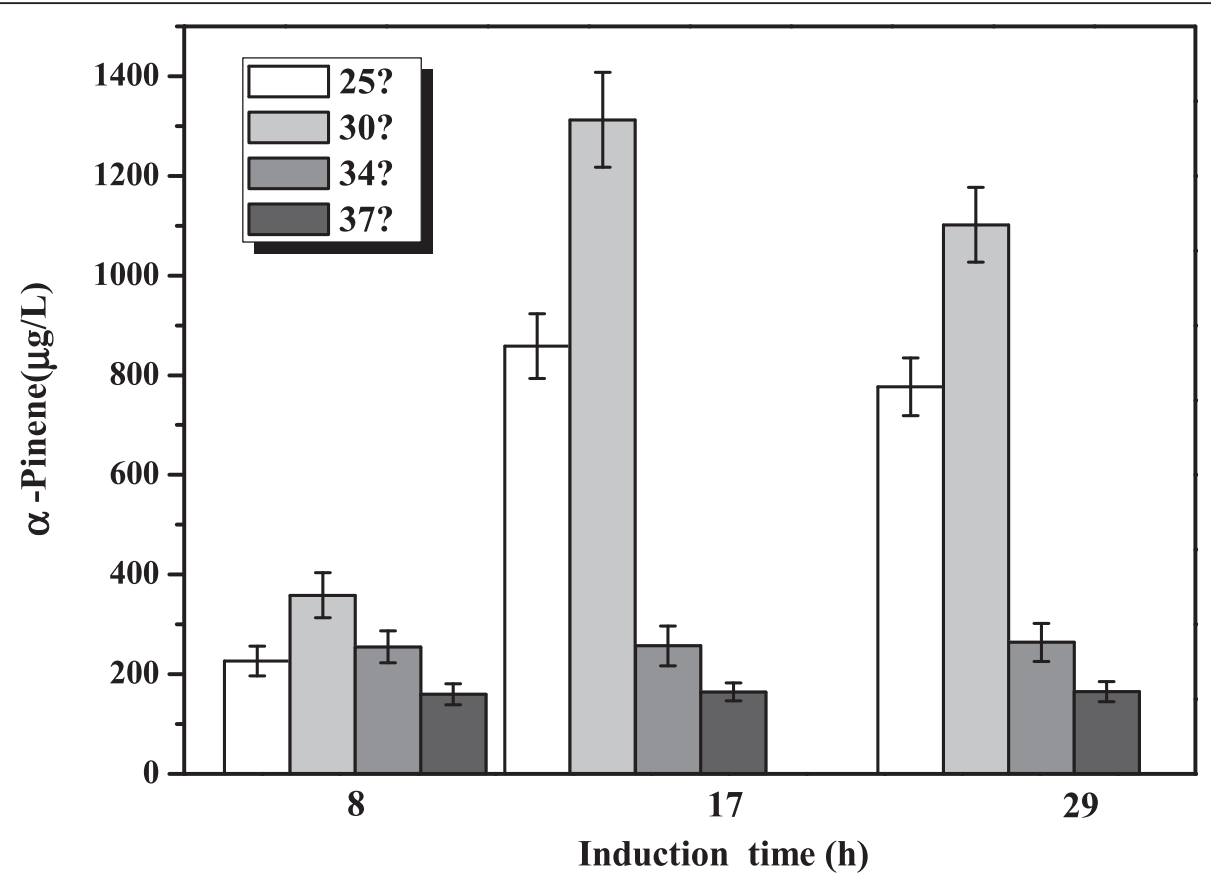

Figure 3 Effect of induction temperature on a-pinene production by YJM28. When $\mathrm{OD}_{600}$ reached 0.6-0.9, cultures were induced at different temperatures: $25^{\circ} \mathrm{C}$ (white color), $30^{\circ} \mathrm{C}$ (light-gray color), $34^{\circ} \mathrm{C}$ (gray color), and $37^{\circ} \mathrm{C}$ (dark-gray color) for $29 \mathrm{~h}$ using $1 \mathrm{mM} \mathrm{IPTG}$. The experiment was conducted in triplicate. 
optimized temperature $30^{\circ} \mathrm{C}$. According to the data shown in Figure 4, the production of $\alpha$-pinene reached a maximum of $1.77 \mathrm{mg} / \mathrm{L}$ at the IPTG concentration of 0.25 $\mathrm{mM}$.

\section{Effect of organic nitrogen source on a-pinene production}

The source of the nitrogen in the medium plays an important role in improving the biosynthesis of desired product [27]. To investigate the effect of organic nitrogen source on $\alpha$-pinene production, seven different organic nitrogen sources were assessed at the above-optimized temperature and IPTG concentration (Figure 5). Among the organic nitrogen supplements tried, the MD beef extract permitted a significantly higher $\alpha$-pinene production than the other organic nitrogen sources. The highest concentration of $\alpha$-pinene was $5.44 \mathrm{mg} / \mathrm{L}$, which was about 16 times as much as the lowest observed. This productivity was higher than the highest previously reported [28].

Based on the above data, the most suitable culture conditions for $\alpha$-pinene production using the engineered strain YJM28 were $30^{\circ} \mathrm{C}, 0.25 \mathrm{mM}$ IPTG and MD beef extract as the organic nitrogen source.

\section{Fed-batch culture of the engineered strains}

To further determine the ability of the engineered strain to produce $\alpha$-pinene at high yield, fed-batch fermentation was carried out using the engineered E. coli BL21 (DE3) strain simultaneously harboring plasmids pYJM27 (pACY-mvaE-mvaS- GPPS2-Pt30) and pYJM14(pTrc-ER G12-ERG8-ERG19-IDI1). During the fed-batch operation, glucose was added intermittently when glucose became depleted, which was indicated by the sharp rise of $\mathrm{pH}$. By controlling the concentration of acetic acid, which is the most deleterious by-product during the culture process of $E$. coli, we maintained the glucose concentration during the fed-batch culture at less than $0.5 \mathrm{~g} / \mathrm{L}$. As shown in Figure 6, $\alpha$-pinene production increased rapidly from $8 \mathrm{~h}$ to $20 \mathrm{~h}$ after induction, and the specific productivity reached $0.018 \mathrm{~g} \mathrm{~h}^{-1} \mathrm{~g}^{-1}$ dry cells. After the cultures were induced for $32 \mathrm{~h}$, $\alpha$-pinene accumulated and reached a maximum concentration of $0.97 \mathrm{~g} \mathrm{~L}^{-1}$ with a specific productivity of $0.004 \mathrm{~g} \mathrm{~h}^{-1} \mathrm{~g}^{-1}$ dry cells, and the conversion efficiency of glucose to $\alpha$ pinene (gram to gram) reached $2.61 \%$. However, the cell density of the engineered strain reached only about 18 , which was rather low for the fed-batch fermentation of E. coli strains. The main reason for the low cell mass of E. coli strain may lie in the retardation of cell growth resulting from overexpression of many heterologous genes. In the previous studies, other monoterpene has been reported to be produced. For example, Carter et al. demonstrated the production of limonene in engineered $E$. coli strain with co-expression of GPP synthase, IPP isomerase and limonene synthase, which could achieve production levels of $5 \mathrm{mg} / \mathrm{L}$ in 24-h culture runs [13]. It is difficult to compare these results to ours primarily because of the following two reasons: one is the different pathways that were used, that is DXP pathway for limonene production and MVA pathway for $\alpha$-pinene synthesis; the other is that they utilized quite different growth and production conditions and strains.

Despite the extensive progress made on $\alpha$-pinene production in E. coli, many possible improvements can be

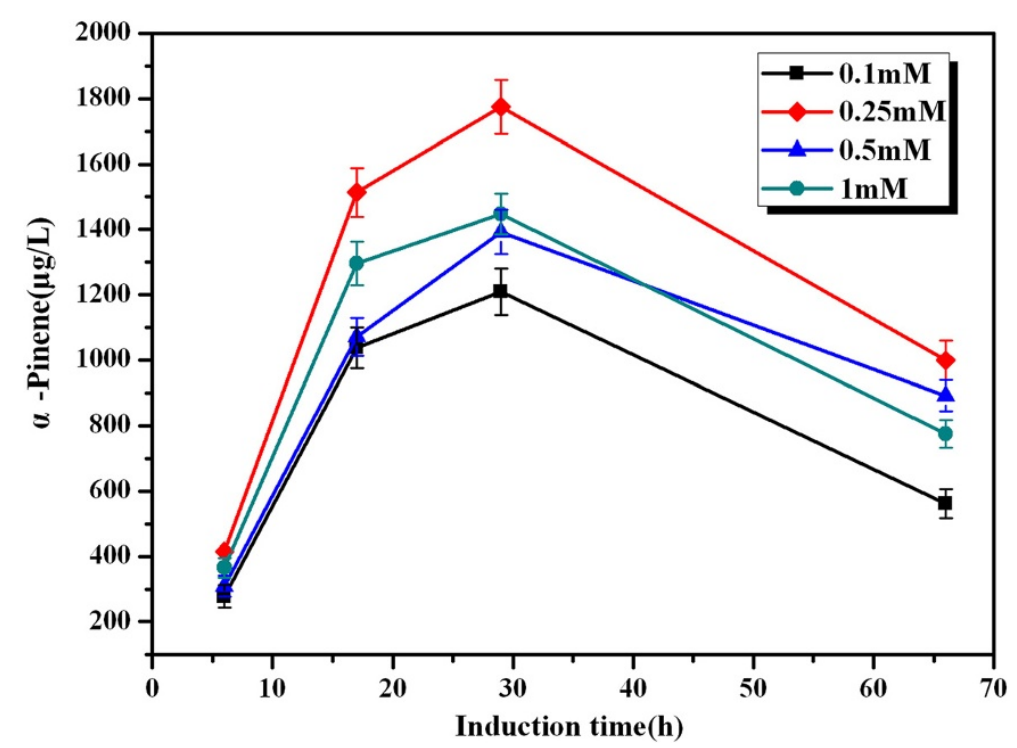

Figure 4 Effect of inducer concentration on a-pinene production by $\mathrm{YJM}_{\mathbf{2}}$. When $\mathrm{OD}_{600}$ reached $0.6-0.9$, cultures were induced at $30^{\circ} \mathrm{C}$ for $66 \mathrm{~h}$ using different concentrations of IPTG: $0.1 \mathrm{mM}(\boldsymbol{\bullet}), 0.25 \mathrm{mM}(\bullet), 0.5 \mathrm{mM}(\boldsymbol{\Delta}), 1 \mathrm{mM}(\bullet)$ The experiment was conducted in triplicate. 


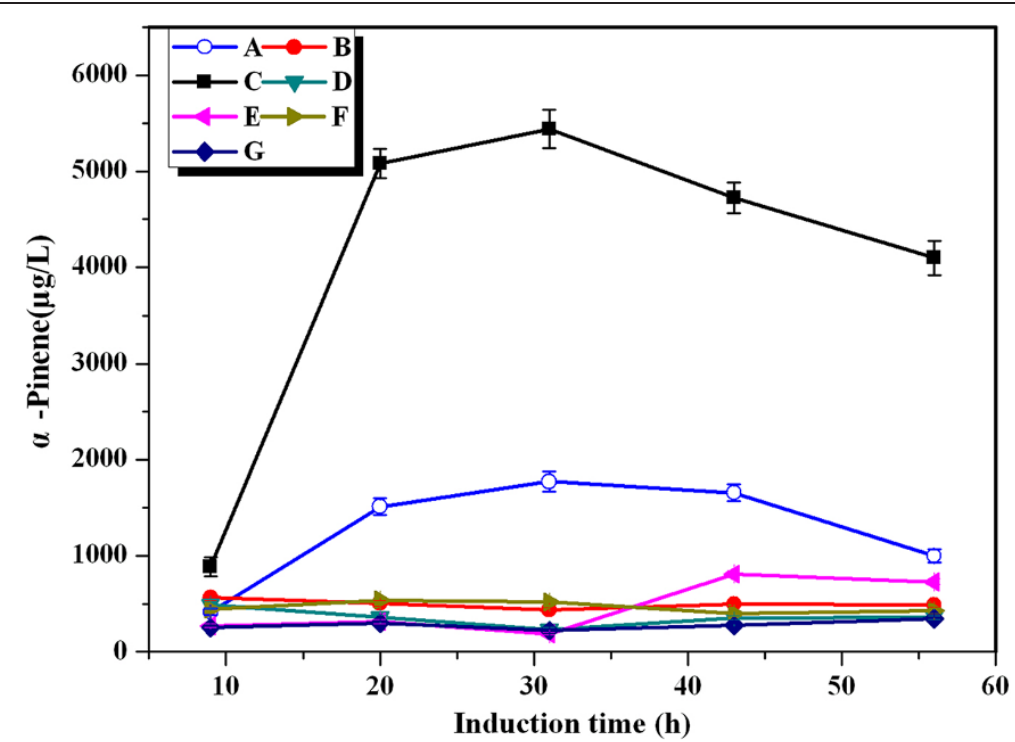

Figure 5 Effect of different organic nitrogen source on a-pinene production by YJM28. A: beef extract (Aladdin, o ); B: beef extract (Beijing AoBoXing Bio-Tech Co., Ltd, $\bullet$ ); C: beef extract powder (MDBio, Inc, $\boldsymbol{m}$ ); D: beef extract powder (Beijing AoBoXing Bio-Tech Co., Ltd, $\mathbf{\nabla}$ ); E: beef extract (Beijing Shuangxuan Microbe Culture Medium Products Factory, 4 ); F: beef extract (Sinopharm Chemical Reagent Co., Ltd, $\boldsymbol{-}$ ); G: beef extract (solarbio, ). When $\mathrm{OD}_{600}$ reached $0.6-0.9$, cultures were induced at $30^{\circ} \mathrm{C}$ for $56 \mathrm{~h}$ using $0.25 \mathrm{mM} I \mathrm{PTG}$. The experiment was performed in triplicate.

achieved to enhance $\alpha$-pinene production. One approach is to optimize the fermentation process by increasing cell density to elevate the yield of product $[29,30]$. Another possibility is employing a chromosome integration technique to decrease the cell growth burden on the host that results from overexpression of heterologous genes [31,32].

\section{Conclusions}

In this study, $\alpha$-pinene production was significantly enhanced by assembling a biosynthetic pathway of $\alpha$-pinene using the heterologous MVA pathway and the GPPS2 and Pt30 genes in an engineered E.coli strain. The final strain, YJM28, containing the biosynthetic pathway of $\alpha$-pinene, accumulated $\alpha$-pinene up to $5.44 \mathrm{mg} / \mathrm{L}$ and $0.97 \mathrm{~g} / \mathrm{L}$ under the flask and fed-batch fermentation conditions, respectively. The conversion efficiency of glucose to $\alpha$-pinene (gram to gram) in the metabolically engineered strain reached $2.61 \%$. To our knowledge, this is the first report on $\alpha$-pinene fedbatch fermentation, and our results represent improvements over previous reports. Therefore, an alternative production

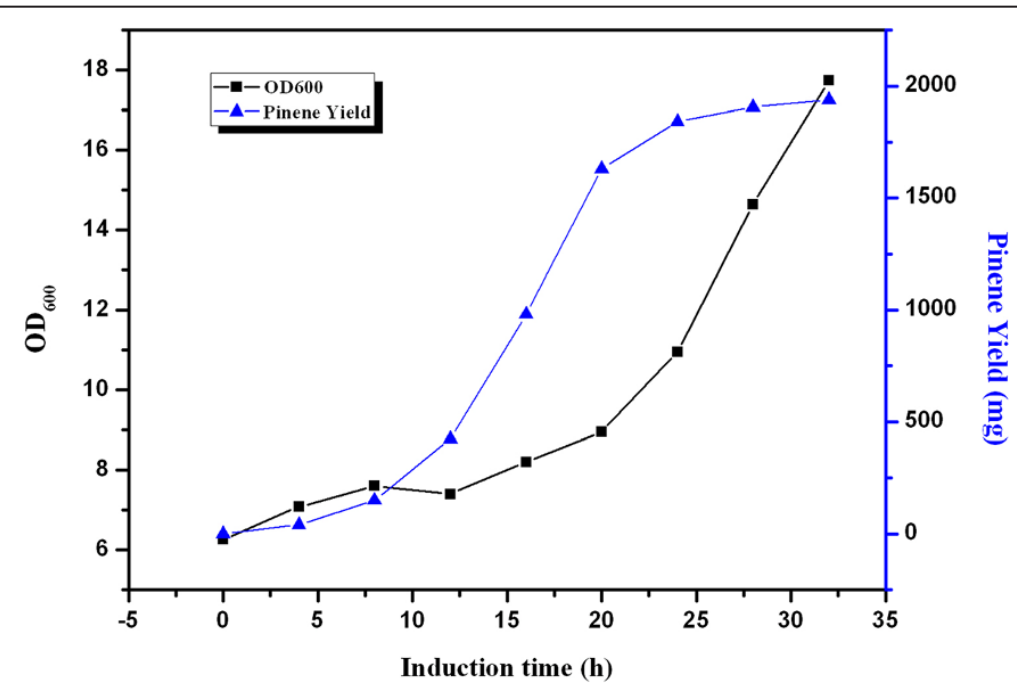

Figure 6 The time course of a-pinene production by YJM28. a-Pinene accumulation ( $\mathbf{\Delta})$ and cell growth (⿶) in YJM28. Induction was carried out at $12 \mathrm{~h}$ at $30^{\circ} \mathrm{C}$ and $0.25 \mathrm{mM}$ IPTG. Other experimental conditions are described in section "Fed-Batch Fermentation". 
system for $\alpha$-pinene from renewable sources via the MVA pathway in $E$. coli has been provided.

\section{Methods}

\section{Bacterial strains, plasmids, and growth conditions}

All strains and plasmids used in this study are listed in Table 1. E. coli strains were grown in LB medium. For $\alpha-$ pinene production, the different strains were cultivated in shake-flask or fed-batch fermentation conditions with medium containing glucose $20 \mathrm{~g} / \mathrm{L}, \mathrm{K}_{2} \mathrm{HPO}_{4} 9.8 \mathrm{~g} / \mathrm{L}$, beef extract $5 \mathrm{~g} / \mathrm{L}$, ferric ammonium citrate $0.3 \mathrm{~g} / \mathrm{L}$, citric acid monohydrate $2.1 \mathrm{~g} / \mathrm{L}, \mathrm{MgSO}_{4} 0.06 \mathrm{~g} / \mathrm{L}$ and $1 \mathrm{ml}$ trace element solution, which included $\left(\mathrm{NH}_{4}\right)_{6} \mathrm{Mo}_{7} \mathrm{O}_{24} \cdot 4 \mathrm{H}_{2} \mathrm{O}$ $0.37 \mathrm{~g} / \mathrm{L}, \mathrm{ZnSO}_{4} \cdot 7 \mathrm{H}_{2} \mathrm{O} 0.29 \mathrm{~g} / \mathrm{L}, \mathrm{H}_{3} \mathrm{BO}_{4} 2.47 \mathrm{~g} / \mathrm{L}, \mathrm{CuSO}_{4}$. $5 \mathrm{H}_{2} \mathrm{O} 0.25 \mathrm{~g} / \mathrm{L}$, and $\mathrm{MnCl}_{2} \cdot 4 \mathrm{H}_{2} \mathrm{O} 1.58 \mathrm{~g} / \mathrm{L}$. If necessary, appropriate antibiotics were added to the culture medium at the following concentrations: ampicillin (Amp, $100 \mu \mathrm{g} /$ $\mathrm{ml})$ and chloramphenicol $(\mathrm{Cm}, 34 \mu \mathrm{g} / \mathrm{ml})$.

\section{Plasmid construction}

Standard DNA manipulations were executed as previously described [33]. Polymerase chain reaction (PCR) was performed using Pfu DNA polymerase (TaKaRa, Dalian, China) according to the manufacturer's instructions.
Construction of plasmids for GPP synthase screening The IspA gene was obtained by PCR using the primers IspA-F (5'-GGGAATTCC- ATATGATGGACTTTCCG CAGCAACTC-3') and IspA-R (5'-GGAAGATCTTT ATTTA-TTACGCTGGATGATGT-3') and E. coli BL21 (DE3) genomic DNA as a template. The isolated IspA gene fragment was excised using BglII and NdeI, followed by insertion into the corresponding sites of the vector pACYCDuet-1 to create pYJM22. The Pt30 gene fragment was acquired by excision from $\mathrm{pGH} / \mathrm{Pt} 30$ with BglII and XhoI and was introduced into the corresponding sites of pYJM22 to create pYJM23 (Figure 7A).

The geranyl diphosphate synthase (GPPS2) gene (GenBank No. AF513112) from Abies grandis and alphapinene synthase (Pt30) gene (GenBank No. AF543530) from Pinus taeda were analyzed by online software (http:// www.genscript.com/cgi-bin/tools/rare_codon_analysis) and optimized to the preferred codon usage of $E$. coli (http:// www.jcat.de/). The codon-optimized GPPS2 gene and Pt30 gene were synthesized by Genray Company with plasmid pGH as the vector (named pGH/GPPS2 and pGH/Pt30, respectively). The GPPS2 gene fragment was obtained by digestion of pGH/GPPS2 with NdeI and BglII and then ligated into the corresponding sites of pACYCDuet-1 to create pYJM24. The Pt30 gene fragment was acquired by excision of pGH/Pt30 with BglII and Xhol and was

Table 1 Strains and plasmids used in this study

\begin{tabular}{|c|c|c|}
\hline Name & Relevant characteristics & References \\
\hline \multicolumn{3}{|l|}{ Strains } \\
\hline E.coli BL21(DE3) & $\mathrm{F}^{-}$ompT hsdS $\mathrm{B}_{\mathrm{B}}\left(\mathrm{r}_{\mathrm{B}}^{-} \mathrm{m}_{\mathrm{B}}^{-}\right) \mathrm{gal} \mathrm{dcm}$ rne131 $\lambda(\mathrm{DE} 3)$ & Invitrogen \\
\hline $\begin{array}{l}\text { Saccharomyces } \\
\text { cerevisiae }\end{array}$ & Type strain & ATCC 4040002 \\
\hline YJM26 & E.coli BL21(DE3)/pYJM23 & This study \\
\hline YJM27 & E.coli BL21(DE3)/pYJM25 & This study \\
\hline YJM28 & E.coli BL21(DE3)/pYJM27,pYJM14 & This study \\
\hline YJM29 & E.coli BL21(DE3)/pYJM28 & This study \\
\hline \multicolumn{3}{|l|}{ Plasmids } \\
\hline pACYCDuet-1 & P15A (pACYC184), $\mathrm{Cm}^{\mathrm{r}}$ & Novagen \\
\hline pTrcHis2B & pBR322 origin, $\mathrm{Amp}^{\mathrm{r}}$ & Invitrogen \\
\hline pYJM14 & pTrcHis2B carrying ERG12, ERG8, ERG19 and IDI1 from Saccharomyces cerevisiae & $\begin{array}{l}\text { (Yang et al., 2011) } \\
{[35]}\end{array}$ \\
\hline pYJM22 & pACYCDuet-1 carrying ispA from E.coli BL21(DE3) & This study \\
\hline pYJM23 & pACYCDuet-1 carrying ispA from E.coli BL21(DE3) and Pt30 from Pinus taeda & This study \\
\hline pYJM24 & pACYCDuet-1 carrying GPPS2 from Abies grandis & This study \\
\hline pYJM25 & pACYCDuet-1 carrying GPPS2 from Abies grandis and Pt30 from Pinus taeda & This study \\
\hline pYJM26 & pACYCDuet-1 carrying mvaE and mvaS from Enterococcus faecalis, GPPS2 from Abies grandis & This study \\
\hline pYJM27 & $\begin{array}{l}\text { PACYCDuet-1 carrying mvaE and mvaS from Enterococcus faecalis, GPPS2 from Abies grandis, Pt } 30 \text { from } \\
\text { Pinus taeda }\end{array}$ & This study \\
\hline pYJM28 & pACYCDuet- 1 carrying Pt30 from Pinus taeda & This study \\
\hline
\end{tabular}



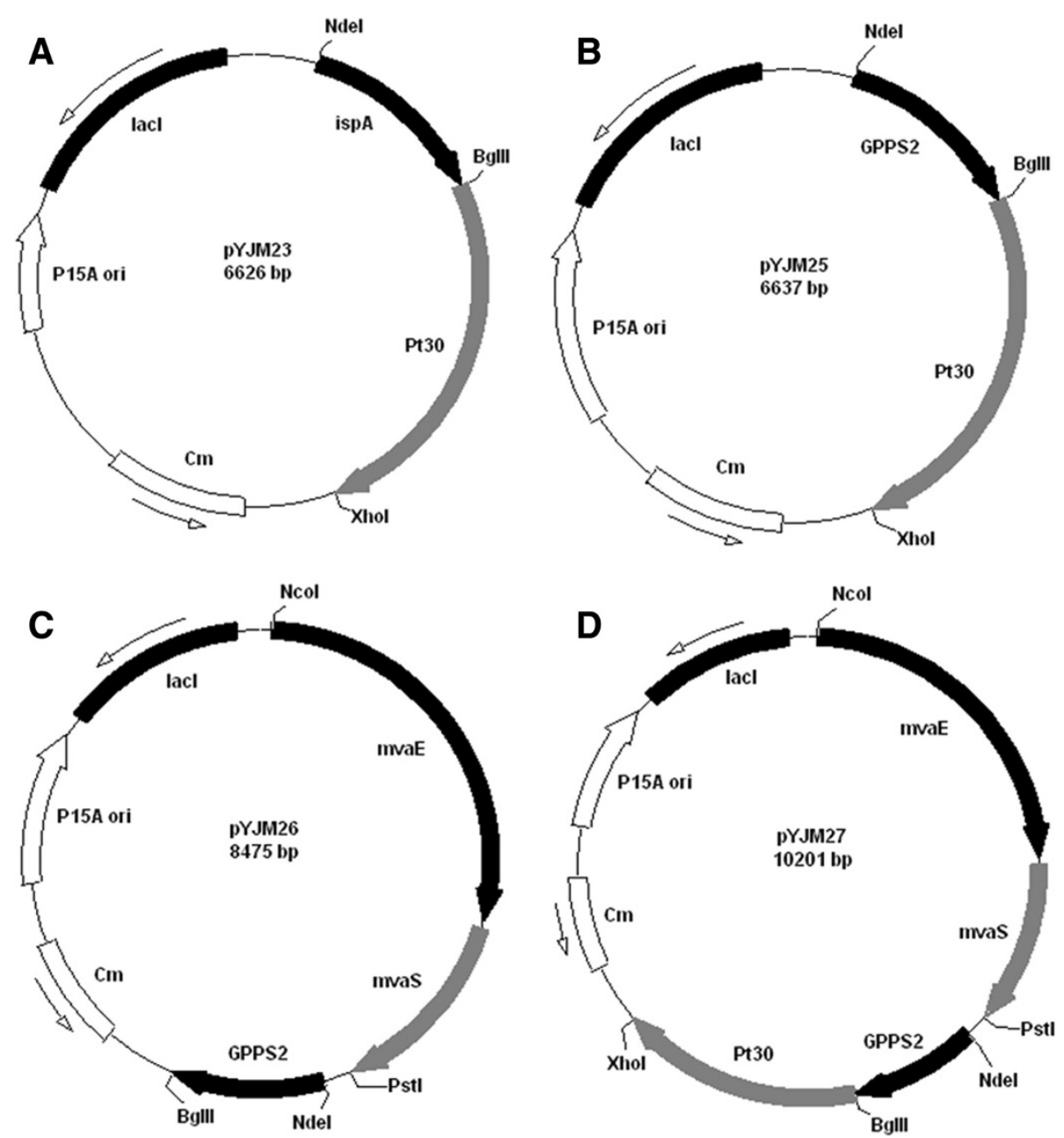

Figure 7 Plasmids used in this study. (A) represented the plasmid pYJM23 harboring ispA from E. coli BL21(DE3) and Pt30 from Pinus taeda; (B) represented the plasmid pYJM25 carrying GPPS2 from Abies grandis and Pt30 from Pinus taeda; (C) represented the plasmid pYJM26 containing mvaE and mvaS from Enterococcus faecalis, GPPS2 from Abies grandis; (D) represented the plasmid pYJM27 carrying mvaE and mvaS from Enterococcus faecalis, GPPS2 from Abies grandis, Pt30 from Pinus taeda.

introduced into the corresponding sites of pYJM24 to create pYJM25 (Figure 7B).

\section{Construction of plasmids for the whole pathway of a- pinene synthesis}

The mvaE-mvaS gene fragment was obtained by excision from pYJM20 [15] using NcoI and PstI and then ligated into the corresponding sites of pYJM24 to create pYJM26 (Figure 7C). The Pt30 gene fragment was acquired by excision from pGH/Pt30 with BglII and XhoI and was introduced into the corresponding sites of pYJM26 to create pYJM27 (Figure 7D).

Plasmid pYJM14 was constructed based on pTrcHis2B by introducing ERG8, ERG12, ERG19 and IDI1 from $S$. cerevisiae [34].

\section{a-Pinene characterization by GC-MS}

Putative $\alpha$-pinene products were analyzed by capillary GC-MS using an Agilent 5975C System chromatograph equipped with an HP-INNOWAX capillary column (30 $\mathrm{m} \times 0.25 \mathrm{~mm} \times 0.25 \mu \mathrm{m}$, Agilent, Palo Alto, CA, USA) The separation conditions were an initial column temperature of $40^{\circ} \mathrm{C}$ for $1 \mathrm{~min}$, an increase of $4^{\circ} \mathrm{C} / \mathrm{min}$ to $70^{\circ} \mathrm{C}$ and an increase of $25^{\circ} \mathrm{C} / \mathrm{min}$ to $300^{\circ} \mathrm{C}$, where it was held for $5 \mathrm{~min}$. The other parameters were an injector temperature of $250^{\circ} \mathrm{C}$; ion source temperature $230^{\circ} \mathrm{C}$; EI $70 \mathrm{eV}$; carrier gas $\mathrm{He}$ at a flow rate of $1 \mathrm{ml}$ $\mathrm{min}^{-1}$; split ratio $1: 7$; mass range $35-300 \mathrm{~m} / \mathrm{z}$. Peak identification was based on a relative retention time and total ion mass spectral comparison with an external standard. 
a-Pinene quantification by gas chromatography (GC)

The $\alpha$-pinene produced by the recombinant strains was quantitatively analyzed by GC as described previously [35]. The E. coli strain was inoculated in $50 \mathrm{ml}$ of fermentation medium containing $34 \mu \mathrm{g} / \mathrm{ml}$ chloramphenicol and/ or $100 \mu \mathrm{g} / \mathrm{ml}$ ampicillin and then cultured at $37^{\circ} \mathrm{C}$ with shaking at $180 \mathrm{rpm}$. When the $\mathrm{OD}_{600}$ of the bacterial culture reached 0.6, the cells were induced by IPTG at a final concentration of $1 \mathrm{mM}$ for $24 \mathrm{~h}$. Then, the off-gas samples were taken from the headspace of the sealed cultures and analyzed by GC.

GC analysis was performed on an Agilent 7890A equipped with a flame ionization detector (FID) and an HP-INNOWAX column $(25 \mathrm{~m} \times 250 \mu \mathrm{m} \times 0.2 \mu \mathrm{m}) . \mathrm{N}_{2}$ was used as carrier gas with a linear velocity of $1 \mathrm{ml} / \mathrm{min}$. The column temperature profile was $50^{\circ} \mathrm{C}$ for $0.5 \mathrm{~min}, 4^{\circ}$ $\mathrm{C} / \mathrm{min}$ increase to $70^{\circ} \mathrm{C}, 25^{\circ} \mathrm{C} / \mathrm{min}$ increase to $250^{\circ} \mathrm{C}$, and $250^{\circ} \mathrm{C}$ for $5 \mathrm{~min}$. The product was characterized by direct comparison with an authentic standard (Sigma-Aldrich). The peak area was converted into $\alpha$-pinene concentration in comparison with a standard curve plotted with a set of known concentrations of $\alpha$-pinene.

\section{Shake-flask cultures}

Shake-flask experiments were performed in triplicate series of $600 \mathrm{ml}$ sealed shake flasks containing $50 \mathrm{ml}$ fermentation medium as described above plus $34 \mu \mathrm{g} / \mathrm{ml} \mathrm{Cm}$ and $100 \mu \mathrm{g} /$ $\mathrm{ml}$ Amp. E. coli strains were cultured in the broth and incubated in a gyratory shaker incubator at $37^{\circ} \mathrm{C}$ and $180 \mathrm{rpm}$. When the $\mathrm{OD}_{600}$ reached 0.6 , IPTG was added to final concentration of $0.25 \mathrm{mM}$, and the culture was further incubated at $30^{\circ} \mathrm{C}$ for $24 \mathrm{~h}$. Then, $1 \mathrm{ml}$ of gas sample from the headspace of the sealed cultures was analyzed as described previously [35] using a gas chromatograph (Agilent 7890A, America) equipped with a FID and an HP-INNOWAX column $(25 \mathrm{~m} \times 250 \mu \mathrm{m} \times 0.2 \mu \mathrm{m})$. Concentrations of $\alpha$ pinene synthesized by bacterial cells were calculated by converting the GC peak area into milligrams of $\alpha$-pinene via a calibration curve.

\section{Optimization of fermentation process \\ Effect of induction temperature}

The E. coli strain was inoculated in $50 \mathrm{ml}$ of fermentation medium and cultured at $37^{\circ} \mathrm{C}$ with shaking at $180 \mathrm{rpm}$. When the $\mathrm{OD}_{600}$ of the bacterial culture reached 0.6-0.9, the shake-flask cultures were incubated at different induction temperatures $\left(25^{\circ} \mathrm{C}, 30^{\circ} \mathrm{C}\right.$, $34^{\circ} \mathrm{C}$ or $37^{\circ} \mathrm{C}$ ) for $29 \mathrm{~h}$ in $1 \mathrm{mM}$ IPTG, and the $\alpha-$ pinene products were assayed.

\section{Effect of IPTG concentration}

The shake-flask culture was incubated in different inducer (IPTG) concentrations $(0.1 \mathrm{mM}, 0.25 \mathrm{mM}$,
$0.5 \mathrm{mM}$ or $1 \mathrm{mM}$ ) at the above-optimized temperature for $66 \mathrm{~h}$, and the $\alpha$-pinene products were measured.

\section{Effect of organic nitrogen source}

The shake-flask cultures were incubated in different organic nitrogen sources (beef extract (solarbio), beef extract (Aladdin), beef extract (Beijing Shuangxuan Microbe Culture Medium Products Factory), beef extract (Sinopharm Chemical Reagent Co., Ltd), beef extract powder (MDBio, Inc), beef extract (Beijing AoBoXing Bio-Tech Co., Ltd) or beef extract powder (Beijing AoBoXing Bio-Tech Co., Ltd)) at the above-optimized temperature and IPTG concentration for $56 \mathrm{~h}$, and the pinene products were calculated.

\section{Fed-batch fermentation}

The strain YJM28 was grown overnight at $37^{\circ} \mathrm{C}$ in $100 \mathrm{ml}$ of LB medium (containing $10 \mathrm{~g}$ of $\mathrm{NaCl}, 5 \mathrm{~g}$ of yeast extract, and $10 \mathrm{~g}$ of tryptone per $1 \mathrm{~L}$ ). These cultures were used to inoculate a 5-L fermentor (BIOSTAT Bplus MO5L, Sartorius, Germany) containing $2 \mathrm{~L}$ of fermentation medium. The temperature was maintained at $30^{\circ} \mathrm{C}$, the $\mathrm{pH}$ was maintained at 7.0 via automated addition of ammonia, and Antifoam 204 was used to prohibit foam development. The stirring speed was first set at $400 \mathrm{rpm}$ and then linked to the dissolved oxygen(DO) concentration to maintain a $20 \%$ saturation of DO. The expression of plasmid-born exogenous gene(s) for $\alpha$-pinene production was initiated at an $\mathrm{OD}_{600}$ of 6 by adding IPTG at a final concentration of $0.25 \mathrm{mM}$, and IPTG was added every $8 \mathrm{~h}$. During the course of fermentation, the residual glucose was measured using a glucose analyzer (SBA-40D, China) and maintained below $0.5 \mathrm{~g} / \mathrm{L}$ by a feeding solution containing $800 \mathrm{~g} / \mathrm{L}$ of glucose at appropriate rates. Then, $\alpha$-pinene accumulation was measured every $60 \mathrm{~min}$ by GC as described in section Optimization of fermentation conditions. At the same time, the growth of the bacterial culture was determined by measuring the $\mathrm{OD}_{600}$ with a spectrophotometer (Cary $50 \mathrm{UV}$-vis, Varian).

\section{Calculations}

The following equation was used to calculate the specific productivity [36].

$$
Q_{p}=\frac{p_{1}-p_{0}}{t_{1}-t_{0}} \times \frac{2}{x_{1}+x_{0}}
$$

where $\mathrm{Q}_{\mathrm{p}}=$ specific production rate $\left(\mathrm{g} \mathrm{h}^{-1} \mathrm{~g}^{-1}\right.$ dry cells); $\mathrm{p}=\alpha$-pinene concentration $(\mathrm{g} / \mathrm{L}) ; \mathrm{t}=$ cultivation time $(\mathrm{h})$, and $\mathrm{x}=$ biomass $(\mathrm{g} / \mathrm{L})$.

Cell culture optical density was measured at $600 \mathrm{~nm}$ using a spectrophotometer (Cary 50UV-vis, VARIAN), and the dry cell weight was calculated according to the coefficient (one $\mathrm{OD}_{600}$ unit corresponded to $0.43 \mathrm{~g} \mathrm{~L}^{-1}$ of dry cell weight). 


\section{Abbreviations}

DMAPP: Dimethylallyl pyrophosphate; IPP: Isopentenyl pyrophosphate; GPP: Geranyl diphosphate; MVA: Mevalonate; MEP: Methylerythritol 4phosphate; IPTG: Isopropyl $\beta$-D-thiogalactoside; PCR: Polymerase chain reaction; GC: Gas chromatography.

\section{Competing interests}

The authors declare that they have no competing interests.

\section{Authors' contributions}

MX and JY developed the idea for the study. JYand HZ designed the research, did the literature review and prepared the manuscript. MX and QN helped to revise the manuscript. ML, YZ, XJ, HF and MR did the lab work, plasmid construction, strain cultivation, Fed-Batch Fermentation and product detection. All authors read and approved the final manuscript.

\section{Acknowledgements}

This work was financially supported by National Key Technology R\&D Program (No. 2012BAD32B06), National High Technology Research and Development Program of China (863 Program, No. SS2013AA050703-2), Knowledge Innovation Program of the Chinese Academy of Sciences (Y112131105)

\section{Author details}

${ }^{1}$ Qingdao Institute of Bioenergy and Bioprocess Technology, Chinese Academy of Sciences, Qingdao 266101, China. ${ }^{2}$ Foreign Languages School, Qingdao Agricultural University, Qingdao 266109, China. ${ }^{3}$ School of Life and Science, Nanjing Agricultural University, Nanjing 210095, China. ${ }^{4}$ College of Bioscience and Biotechnology, Shenyang Agricultural University, Shenyang 110866, China. ${ }^{5}$ College of Chemical Engineering and Technology, Wuhan University of Science and Technology, Wuhan 430081, China.

Received: 11 January 2013 Accepted: 15 April 2013 Published: 30 April 2013

\section{References}

1. Burke C, Croteau R: Geranyl diphosphate synthase from Abies grandis: cDNA isolation, functional expression, and characterization. Arch Biochem Biophys 2002, 405(1):130-136.

2. Behr A, Johnen L: Myrcene as a natural base chemical in sustainable chemistry: a critical review. ChemSusChem 2009, 2(12):1072-1095.

3. Brown HC, Ramachandran PV: Asymmetric reduction with chiral organoboranes based on. alpha.-pinene. Acc Chem Res 1992, 25(1):16-24

4. Kirby J, Keasling JD: Biosynthesis of plant isoprenoids: perspectives for microbial engineering. Annu Rev Plant Biol 2009, 60:335-355.

5. Harvey BG, Wright ME, Quintana RL: High-density renewable fuels based on the selective dimerization of pinenes. Energy Fuel 2009, 24(1):267-273.

6. Meylemans HA, Quintana RL, Harvey BG: Efficient conversion of pure and mixed terpene feedstocks to high density fuels. Fuel 2012, 97:560-568.

7. Chang MCY, Keasling JD: Production of isoprenoid pharmaceuticals by engineered microbes. Nat Chem Biol 2006, 2(12):674-681.

8. Schmidt-Dannert C, Umeno D, Arnold FH: Molecular breeding of carotenoid biosynthetic pathways. Nat Biotechnol 2000, 18(7):750-753.

9. Clomburg JM, Gonzalez R: Biofuel production in Escherichia coli: the role of metabolic engineering and synthetic biology. Appl Microbiol Biotechnol 2010, 86(2):419-434.

10. Leonard E, Lim KH, Saw PN, Koffas MAG: Engineering central metabolic pathways for high-level flavonoid production in Escherichia coli. Appl Environ Microbiol 2007, 73(12):3877-3886.

11. Steinbuchel A: Production of rubber-like polymers by microorganisms. Curr Opin Microbiol 2003, 6:261-270

12. Reiling KK, Yoshikuni Y, Martin VJJ, Newman J, Bohlmann J, Keasling JD: Mono and diterpene production in Escherichia coli. Biotechnol Bioeng 2004, 87(2):200-212.

13. Carter OA, Peters RJ, Croteau R: Monoterpene biosynthesis pathway construction in Escherichia coli. Phytochemistry 2003, 64(2):425-433.

14. Martin VJJ, Pitera DJ, Withers ST, Newman JD, Keasling JD: Engineering a mevalonate pathway in Escherichia coli for production of terpenoids. Nat Biotechnol 2003, 21(7):796-802.
15. Yang J, Xian M, Su S, Zhao G, Nie Q, Jiang X, Zheng Y, Liu W: Enhancing production of bio-isoprene using hybrid MVA pathway and isoprene synthase in E. Coli. PLOS One 2012, 7(4):e33509.

16. Zhao Y, Yang J, Qin B, Li Y, Sun Y, Su S, Xian M: Biosynthesis of isoprene in Escherichia coli via methylerythritol phosphate (MEP) pathway. Appl Microbiol Biotechnol 2011, 90:1915-1922.

17. Yan Y, Liao JC: Engineering metabolic systems for production of advanced fuels. J Ind Microbiol Biotechnol 2009, 36(4):471-479.

18. Schmidt F: Optimization and scale up of industrial fermentation processes. Appl Microbiol Biotechnol 2005, 68(4):425-435.

19. Ahamad M, Panda B, Javed S, Ali M: Production of mevastatin by solidstate fermentation using wheat bran as substrate. Res J Microbio/ 2006, 1:443-447.

20. Alexeeva Y, Ivanova E, Bakunina IY, Zvaygintseva T, Mikhailov W: Optimization of glycosidases production by Pseudoalteromonas issachenkonii KMM 3549T. Lett Appl Microbiol 2002, 35(4):343-346.

21. Sanchez $d G N$, Salvador $V$ : Effect of temperature on protein quality in bacterial inclusion bodies. FEBS Lett 2006, 580(27):6471-6476.

22. Hunke S, Betton JM: Temperature effect on inclusion body formation and stress response in the periplasm of Escherichia coli. Mol Microbiol 2003 50(5):1579-1589.

23. de Groot NS, Ventura S: Effect of temperature on protein quality in bacterial inclusion bodies. FEBS Lett 2006, 580(27):6471-6476.

24. Bentley WE, Mirjalili N, Andersen DC, Davis RH, Kompala DS: Plasmidencoded protein: The principal factor in the "metabolic burden" associated with recombinant bacteria. Biotechnol Bioeng 1990, 35(7):668681 .

25. Glick BR: Metabolic load and heterologous gene expression. Biotechnol Adv 1995, 13(2):247-261

26. Donovan RS, Robinson C, Glick B: Review: optimizing inducer and culture conditions for expression of foreign proteins under the control of thelac promoter. J Ind Microbiol Biotechnol 1996, 16(3):145-154.

27. Torija MJ, Beltran G, Novo M, Poblet M, Rozès N, Guillamón JM, Mas A: Effect of the nitrogen source on the fatty acid composition of Saccharomyces cerevisiae. Food Microbiol 2003, 20(2):255-258.

28. Bokinsky G, Peralta-Yahya PP, George A, Holmes BM, Steen EJ, Dietrich J, Lee TS, Tullman-Ercek D, Voigt CA, Simmons BA, et al: Synthesis of three advanced biofuels from ionic liquid-pretreated switchgrass using engineered Escherichia coli. Proc Natl Acad Sci 2011, 108(50):19949-19954.

29. Wang D, Li Q, Song Z, Zhou W, Su Z, Xing J: High cell density fermentation via a metabolically engineered Escherichia coli for the enhanced production of succinic acid. J Chem Technol Biotechnol 2011 86(4):512-518

30. Chen N, Huang J, Feng Z, Yu L, Xu Q, Wen T: Optimization of fermentation conditions for the biosynthesis of L-threonine by Escherichia coli. Appl Biochem Biotechnol 2009, 158(3):595-604.

31. Kuhlman TE, Cox EC: Site-specific chromosomal integration of large synthetic constructs. Nucleic Acids Res 2010, 38:e92.

32. Chen HT, Lin MS, Hou SY: Multiple-copy-gene integration on chromosome of Escherichia coli for beta-galactosidase production. Kor J Chem Eng 2008, 25:1082-1087.

33. Sambrook J, Russell DW: Molecular cloning: a laboratory manual. 3rd edition. Cold Spring Harbor: Cold Spring Harbor Laboratory Press; 2001.

34. Yang J, Zhao G, Sun Y, Zheng Y, Jiang X, Liu W, Xian M: Bio-isoprene production using exogenous MVA pathway and isoprene synthase in Escherichia coli. Bioresour Technol 2011, 104:642-647.

35. Kolb B: Headspace sampling with capillary columns. J Chromatogr A 1999, 842(1):163-205.

36. Tashiro Y, Takeda K, Kobayashi G, Sonomoto K, Ishizaki A, Yoshino S: High butanol production by Clostridium saccharoperbutylacetonicum N1-4 in fed-batch culture with $\mathrm{pH}$-stat continuous butyric acid and glucose feeding method. J Biosci Bioeng 2004, 98(4):263-268.

doi:10.1186/1754-6834-6-60

Cite this article as: Yang et al:: Metabolic engineering of Escherichia coli for the biosynthesis of alpha-pinene. Biotechnology for Biofuels 2013 6:60. 